\title{
Correlating Students' Educational Background, Study Habits, and Resource Usage with Learning Success in Medical Histology
}

\author{
Daniel Selvig, ${ }^{1}$ Louisa W. Holaday, ${ }^{1}$ Joel Purkiss, ${ }^{2,3}$ Michael Hortsch ${ }^{1,3 *}$ \\ ${ }^{1}$ Department of Cell and Developmental Biology, University of Michigan Medical School, Ann Arbor, Michigan \\ ${ }^{2}$ Office of Student Education, University of Michigan Medical School, Ann Arbor, Michigan \\ ${ }^{3}$ Department of Medical Education, University of Michigan Medical School, Ann Arbor, Michigan
}

\begin{abstract}
Histology is a traditional core basic science component of most medical and dental education programs and presents a didactic challenge for many students. Identifying students that are likely to struggle with histology would allow for early intervention to support and encourage their learning success. To identify student characteristics that are associated with learning success in histology, three first-year medical school classes at the University of Michigan (>440 students) were surveyed about their educational background, attitudes toward learning histology, and their use of histology learning strategies and resources. These characteristics were linked with the students' quiz and examination results in histology. Students who reported previous experience in histology or pathology and hold science or biomedical science college degrees usually did well in histology. Learning success in histology was also positively associated with students' perception that histology is important for their professional career. Other positive indicators were in-person participation in teacher-guided learning experiences, specifically lecture and laboratory sessions. In contrast, students who relied on watching histology lectures by video rather than going to lectures in-person performed significantly worse. These characteristics and learning strategies of students who did well in this very visual and challenging study subject should be of help for identifying and advising students early, who might be at risk of failing a histology course or component. Anat Sci Educ 8: 1-11. ( 2014 American Association of Anatomists.
\end{abstract}

Key words: histology education; microscopic anatomy; medical education; microanatomy; virtual microscopy; educational technology; e-learning; study habits

\section{INTRODUCTION}

Histology is usually taught during the initial phase of medical and dental curricula and poses several unique challenges to new learners. Few students have previously been exposed to

${ }^{*}$ Correspondence to: Dr. Michael Hortsch; Department of Cell and Developmental Biology, University of Michigan Medical School, 109 Zina Pitcher Place, Ann Arbor, MI 48109, USA. E-mail: hortsch@umich.edu

Grant sponsor: Center for Research on Learning and Teaching 201112 Investigating Student Learning Grant, University of Michigan

Received 10 December 2013; Revised 14 February 2014; Accepted 11 March 2014.

Published online 4 April 2014 in Wiley Online Library (wileyonlinelibrary.com). DOI 10.1002/ase.1449

(c) 2014 American Association of Anatomists histology or pathology during their college education and the interpretation of microscopic images requires some visual perceptive and analytical abilities (Notzer and Aronson, 1979; Hamilton et al., 2009; Helle et al., 2010, Holaday et al., 2013). As a result, a number of students find the material difficult to learn and need extra time and didactic support to develop a successful study strategy. Considering that the overall hours of instruction in histology at medical and dental schools in the United States has consistently declined in the past decades, this should be of special concern (Drake et al., 2009; Burk et al., 2013). Although a variety of factors might potentially influence learning success at the medical school level, the project described in this publication started with the hypothesis that there may be some identifiable characteristics of students who struggle in histology and other characteristics of students who do well in histology. In the analysis reported here, several common characteristics were identified among students who are successful learners of histology in 
contrast to those who are at risk of failing a histology course or component.

Several studies have looked at overall predictors of students' academic success in medical school and most report no or only a weak association with academic performance prior to medical school (Rhoads et al., 1974; Dickman et al., 1980; Zeleznik et al., 1983; Canaday and Lancaster, 1985; Koenig, 1992; Smith, 1998; Huff and Fang, 1999; Ferguson et al., 2002; Lievens et al., 2002; Tektas et al., 2013). In contrast, very few studies have tried to associate academic background and learning success for specific subjects that are taught during the first two years of medical school (Steele and Barnhill, 1982; Forester et al., 2002). For histology or pathology only specific variables, such as premedical coursework and visual perceptual abilities, have been evaluated for their impact on students' learning (Forester et al., 2002; Helle et al., 2010). In addition, several studies investigated how specific teaching modalities, such as online course organization, virtual microscopy, and computer-assisted teaching tools (Ogilvie et al., 1999; Bloodgood and Ogilvie, 2006; Triola and Holloway, 2011), influence students' learning in histology. Several of these learning resources were reported to be associated with increases in students' engagement and learning outcomes (Heidger et al., 2002; Lei et al., 2005; Kumar et al., 2006; Husmann et al., 2009). However, none of these studies tried to develop a comprehensive profile of students doing well or of students receiving failing grades in histology. Only few publications describe successful general strategies, such as improving study skills, that help students in academic trouble to remediate their deficiencies (Cleland et al., 2013; McLaughlin et al., 2013; Stegers-Jager et al., 2013) and none addresses students specifically at risk of failing a histology course or component.

In this report, the educational background, motivation, learning strategies, and resource usage of three first-year medical school classes at the University of Michigan were linked with their learning success in histology as measured by their end-of-year cumulative quiz and examination performance (final cumulative histology score). The results indicate that a number of different factors are associated with students doing well or with students scoring low on histology examinations. This knowledge should be helpful in identifying students who might be at risk of failing this basic science subject.

\section{MATERIALS AND METHODS}

\section{Histology as Part of the Medical School Curriculum at the University of Michigan}

The University of Michigan Medical School's (UMMS) integrated curriculum is designed to lead to an M.D. degree within a 4-year period. Approximately, 170 students enter this program each year. About 10-12 students each year are simultaneously enrolled in the Michigan Medical Scientist Program (MSTP), which leads to an M.D., as well as a Ph.D. degree. Work for the Ph.D. degree is usually inserted between Years 2 and 3 of the M.D. program. During the first year of Medical School (M1), histology is taught in eight organsystem-based sequences from September through March. Each one of these sequences contains one to five traditionalstyle histology lectures, which are followed by 3-hour long, faculty-guided laboratory sessions. In total, the M1 histology component offers 26 hours of lectures and 21 laboratory ses- sions. Each laboratory session begins with a PowerPoint introduction to the virtual slide material lasting approximately $30 \mathrm{~min}$. Subsequently, students have the opportunity to work on their laboratory assignments using the histology website (UMMS, 2014) in the presence of histology teaching faculty. During these sessions, they also have the option of viewing histological glass slides with light microscopes, which are set up in one of the laboratory rooms. Poster-size, labeled electron micrographs are displayed in the hallways outside the laboratory rooms and remain available to students throughout each sequence period. Lecture handouts and laboratory introduction PowerPoint files can be downloaded by the students from the UMMS histology website (UMMS, 2014). Paper copies of the lecture handouts are also made available to all students prior to all lectures.

\section{Histology Resources Available to M1 Students at the University of Michigan}

The UMMS histology website (UMMS, 2014) serves as the central access point for many of the electronic learning tools available to University of Michigan medical students. The website not only allows the downloading of passwordprotected histology resources (lecture handouts and various series of PowerPoint files), but also contains learning objectives, laboratory instructions, and links to the University of Michigan virtual slide collection, which are openly accessible under a Creative Commons license. At the end of each organ-organized web section, are a number of review problems and multiple-choice practice questions. Students may access the virtual histology slides outside of scheduled laboratory hours, thus they can complete laboratory assignments without faculty assistance. Attendance of histology lectures and laboratory sessions is neither compulsory nor documented. The supplemental study resources, which were created by Michigan histology teaching faculty members, include histological Whiteboard Drawings (as PowerPoint files) and Summary Sheets (PDF files; this resource was not available to the first class participating in the survey) which both summarize the most salient points of a study topic in either graphic or table format, Labeled Micrograph PowerPoint files with annotated still shots of virtual histology slides, "Review and Look-Alike" PowerPoint files that specifically address similarly-looking histological structures and tissues, and the "SecondLook" PowerPoint series that provides students with a self-evaluation tool to test their preparedness before quizzes and examinations (UMMS, 2013). The purchase of one of the following histology textbooks or atlases was strongly recommended at the beginning of the M1 histology component, but was not an enforced requirement: Young et al., 2006; Ross and Pawlina, 2011; Mescher, 2013.

\section{Lecture Video Capture System}

All lectures, but none of the laboratory sessions, are videorecorded and these video recordings are available for replay and download from a password-protected website. During the 2010-2011 academic years, the video encoding and streaming system, Helix Universal Mobile Server, version 14.0.0.348, (RealNetworks Inc., Seattle, WA) was used. It only recorded the lecture slides and the voice of the lecturer. Enounce 2xAV software (Enounce Inc., Palo Alto, CA) was offered as an add-on to provide students with the ability for 
multispeed playback. For video download (including use on mobile devices such as iPhones), Wirecast, version 2.6.2 software (Telestream Corp., Nevada City, CA) was used. Starting with the 2011-2012 academic year, the MediaSite video capturing system, version 5.5, (Sonic Foundry Inc., Madison, WI) was used. The MediaSite playback software, version 6.1, (Sonic Foundry Inc., Madison, WI) allows learners to simultaneously view both the lecturer video image and the screen capture window synchronously in the same window.

\section{Examination of Students' Knowledge in Histology}

All University of Michigan M1 students are tested for their proficiency in various subjects by weekly online quizzes and an end-of-sequence final examination. Each student is required to attain an overall $75 \%$ average for each sequence to receive a Pass. No letter grades are given during the first two years of the 4-year Michigan M.D. program. Usually, a total of eight multiple-choice-based questions are asked per histology lecture and laboratory session. The final cumulative histology score is based on about 180 questions over the course of the entire M1 histology component and is used in the analysis presented here as the measure of students' learning success in the M1 histology component.

\section{Structure of the Survey and Data Collection}

The results presented in this article are derived from an online survey that was administered following the final histology module of the first-year histology component to the UMMS classes of 2014, 2015, and 2016. The survey items were initially drafted by the histology component director (M.H.) whose experience in histology education, and knowledge regarding the various resources and study patterns common to students at our institution, promoted content validity. The survey then underwent a careful review and editing process. The involvement of two medical students (D.S. and L.W.H.), who provided significant input as peers of the target audience, was key to this process. Further, a faculty member with expertise and significant experience in survey research methodology (J.P.) also contributed to the review and editing process. Participation was entirely voluntary, but was encouraged by the random drawing of four $\$ 70$ cash prizes from among participating students. The survey was constructed using the Qualtrics online survey service (Qualtrics, 2014) and consisted of 20 question sets. Each question set addressed between one and 18 different points or resources with ranges of two to five possible answers. For instance, students responded to questions regarding their histology study habits and their use of 18 different histology educational resources. For each resource, students were asked how frequently they used that resource on a five-point Likert scale ("Always", "Frequently", "Moderately", "Rarely", or "Never"), and were also asked whether their use of that resource increased, decreased, or stayed the same over the course of the academic year. Four questions allowed participating students to enter a text-based, open-ended response. Demographic characteristics and past educational experiences were also assessed. Survey questions established personal background, such as type of college major, time since graduation, previous relevant coursework, and laboratory experiences. The use of the following available histology resources was also evaluated: lecture attendance, lecture videos, laboratory sessions, and usage of PowerPoint files, manuals, textbooks, and other available resources. Additional questions focused on histology study habits, specifically individual versus study group and study time spent per lecture topic. Not all participating students answered all questions, resulting in some variability in the $N$ of total responses to each question. Prior to the analysis of the data, a study contributor who was not personally involved in teaching the M1 histology component linked survey responses with the overall cumulative histology examination results and rendered all survey responses anonymous. Before the administration of the survey, the project received an Institutional Review Board (IRB) exemption from the University of Michigan medical IRB panel (application number HUM00048823).

\section{Statistical Analysis of Data}

To perform statistical analysis, IBM SPSS Statistics, version 19 (IBM Corp., Armonk, NY) was used. Descriptive statistics including percentages, means, and standard deviations were calculated to summarize student response patterns for the various survey items. When comparing mean final cumulative histology scores for groups, we used two-tailed paired-sample t-tests (to compare only two groups' means) and one-way ANOVA with Tukey's B post hoc tests (when comparing more than two groups' means). We used a $P$-value $<0.05$ as the standard for statistical significance and a $P$-value $<0.01$ as highly significant.

\section{RESULTS}

\section{Association between Students' Background Characteristics and Final Cumulative Histology Score}

In the first set of survey questions, the educational background of participating students was assessed. Students were asked whether they had worked in a basic science research laboratory during the last 5 years, whether they had been exposed to histology or pathology before medical school, whether they were MSTP students, whether they were colorblind, about their undergraduate major, and the number of years that had passed between graduation from undergraduate studies and starting medical school. The average final cumulative histology score grade was linked with student's survey answers and tested for statistically significant differences. The results for the questions asking about student's educational background are shown in Tables 1 and 2. Several items did not demonstrate statistically significant differences. Students with previous work experience in a basic science research laboratory did not score better in histology examinations. However, students who reported to have been previously exposed to histology or pathology exhibited a significantly better final cumulative histology score than those who did not (Table 1). MSTP students scored better than those not in the MSTP program. However, this difference approached but did not reach statistical significance. Also, students reporting being colorblind did not score significantly worse than students with no such handicap. Although the time passed since graduating from college was not significantly associated with students' performance in histology (Table 1), there was a significant difference in the final 
Statistical Analysis of Final Cumulative Histology Scores and Students' Personal and Educational Background Characteristics

\begin{tabular}{|c|c|c|c|}
\hline Question & $\begin{array}{c}\text { Yes } \\
\text { Mean ( } \pm \text { SD) } N\end{array}$ & $\begin{array}{c}\text { No } \\
\text { Mean ( } \pm \text { SD) } N\end{array}$ & T-test $^{\mathrm{b}} ; \boldsymbol{P}$-value \\
\hline $\begin{array}{l}\text { Have you worked in a } \\
\text { basic science research } \\
\text { laboratory in the last } 5 \text { years? }\end{array}$ & $88.50( \pm 6.09) 326$ & $88.40( \pm 5.44) 116$ & $0.056 ; 0.955$ \\
\hline $\begin{array}{l}\text { Have you been exposed to } \\
\text { histology or pathology before } \\
\text { medical school? }\end{array}$ & $89.50( \pm 5.90) 146$ & $88.00( \pm 5.89) 298$ & $2.44 ; 0.015^{a}$ \\
\hline $\begin{array}{l}\text { Are you in the University of } \\
\text { Michigan MSTP Program? }\end{array}$ & $90.20( \pm 5.02) 33$ & $88.40( \pm 5.99) 410$ & $1.70 ; 0.057$ \\
\hline Are you colorblind? & $87.19( \pm 6.25) 13$ & $88.50( \pm 5.91) 429$ & $-0.79 ; 0.429$ \\
\hline
\end{tabular}

cumulative histology scores based on the type of undergraduate major (Table 2). Students with a biomedical degree (Biology, Biomedical engineering, Biochemistry, Cell and Molecular Biology, and others) scored significantly better in histology than students who received a nonscience degree (Business administration, Languages, Music, History, etc.). Students who received a science degree that was not in a biomedical field (such as Physics, Mathematics, Engineering, and others) had an intermediate final cumulative histology score with no significant difference from the two other groups.

\section{Association between Students' Study Attitude/ Habits and Final Cumulative Histology Score}

In a second set of survey questions, students were asked about their histology study habits and their attitude toward learning histology. These answers were again linked with students' final cumulative histology performance and tested for statistically significant differences. Quantitative results for these questions are displayed in Table 3. Although there is a slight increase in the final cumulative histology score with increased study time, a statistical analysis indicated it is not significant. Similarly, the few students reporting that they "never" or "rarely" studied histology alone had final cumulative histology scores above the mean of all participating students. However, the ANOVA $P$ value of 0.055 did not breach the threshold for statistical significance. In contrast, when students were asked how relevant they believed histology to be to their future professional career, their answers from "Not at all relevant" to "Very relevant" associated with their final cumulative histology scores to a highly significant degree (Table 3).

\section{Association between Students' Resource Usage and Final Cumulative Histology Score}

A third group of survey questions asked students for their use of specific histology learning resources, such as lectures, lecture videos, laboratory sessions, and a number of supplemental traditional and electronic learning tools. Only a few reported usage-frequencies of these supplemental learning resources exhibit a statistically significant association with the final cumulative histology examination score (Table 4). Specifically, the use of online multiple-choice practice questions was highly significantly associated with a high final cumulative histology score. A comparison of histology laboratory attendance with the use of the laboratory introduction PowerPoint file and the medical histology website outside of laboratory hours also indicates that higher final cumulative histology scores are statistically linked to in-person attendance of these learning opportunities (Table 4). When asking students whether they attended lecture in person or watched a downloadable, recorded lecture video, differences in final cumulative course scores were highly significant (Fig. 1). Tukey's B post hoc tests comparing mean final cumulative histology scores between students grouped according to their response to the question about attending lecture in person, found that students who indicated they "always" attended lecture had the highest mean score $(90.14 \%)$, and they differed significantly from those who indicated "moderate" attendance $(87.14 \%)$ and "rare" attendance $(87.30 \%)$. Tukey's B post hoc tests for viewing lecture videos indicate that those students reporting "frequent" use of videos had the lowest final cumulative examination score $(86.71 \%)$, and this group differs significantly from those reporting "rare" use $(89.27 \%)$ or "never" using lecture videos $(90.50 \%)$. Additionally, students indicating they "never" used lecture videos also did better and differed significantly from those indicating a use of lecture videos at a "moderately" $(87.15 \%)$ or "always" $(88.06 \%)$ level.

\section{DISCUSSION}

This report presents an analysis of various factors that affect medical students' academic performance in histology. As learning is an individual and highly complex process, it was expected that the study would identify a number of elements with varying degrees of influence on how students learn and perform in this basic science subject. Some of these factors are related to students' educational background and specific 




abilities or challenges, others to learning strategies that are adopted by individual students and the use of various learning opportunities that are offered. In addition to the aspects that were identified in this study, additional parameters that make students successful or struggling histology learners most likely exist and remain to be elucidated.

\section{Association between Students' Background Characteristics and Final Cumulative Histology Score}

Any class of medical students at any medical school will likely have a wide range of educational backgrounds. Multiple studies from different countries indicate that premedical grades and the type of college degree have little or no impact on students' general success in medical school (Zeleznik et al., 1983; Smith, 1998; Ferguson et al., 2002; Dixon, 2012; Tektas et al., 2013). Two reports indicate that students with a nonscience undergraduate degree are not at higher risk of academic trouble in medical school than students with an undergraduate degree in a science field (Dickman et al., 1980; Huff and Fang, 1999). In contrast, when looking at learning success in histology during the first year of medical school, the type of undergraduate college degree was highly associated with the final cumulative examination score for histology. This indicates that although students with a nonscience background are not generally disadvantaged to succeed in medical school, they might struggle at least initially in specific subjects, such as histology. In addition, a previous exposure to histology or pathology provides a statistically significant advantage (Table 1). This finding supports two earlier studies, which reported that premedical experience in histology improves the performance in medical histology courses (Canaday and Lancaster, 1985; Forester et al., 2002). Canaday and Lancaster (1985) reported no similar effect for several other first-year medical school subjects, specifically gross anatomy, biochemistry, or embryology.

As the academic requirements for a student to be admitted into the University of Michigan MSTP are especially high, a survey question also asked for membership in the program to find out whether these students perform better in histology than non-MSTP M1 students. Members of the University of Michigan MSTP had a higher cumulative histology grade than their classmates (Table 1). However, this difference $(P=0.057)$ did not breach the threshold for statistical significance. It should be noted that the number of MSTP students is relatively small ( 33 respondents) and it is possible that the difference in the final cumulative histology score might become statistically significant if a larger number of students were sampled.

As histology has a central visual component, colorblind students might have a disadvantage in recognizing and interpreting histological images. Poole et al. (1997) reported that deficiencies in color vision associate with an increase in diagnostic errors by histopathology and laboratory professionals. Our data obtained from 13 medical students, who reported to be colorblind, indicated a slightly lower final cumulative histology score that did not approach statistical significance $(P=0.429$; Table 1). Personal interactions with some of these students revealed that many colorblind individuals develop compensatory strategies when learning histology, which appear to at least partially negate their disadvantage in analyzing colored histological images. Still, special care should 


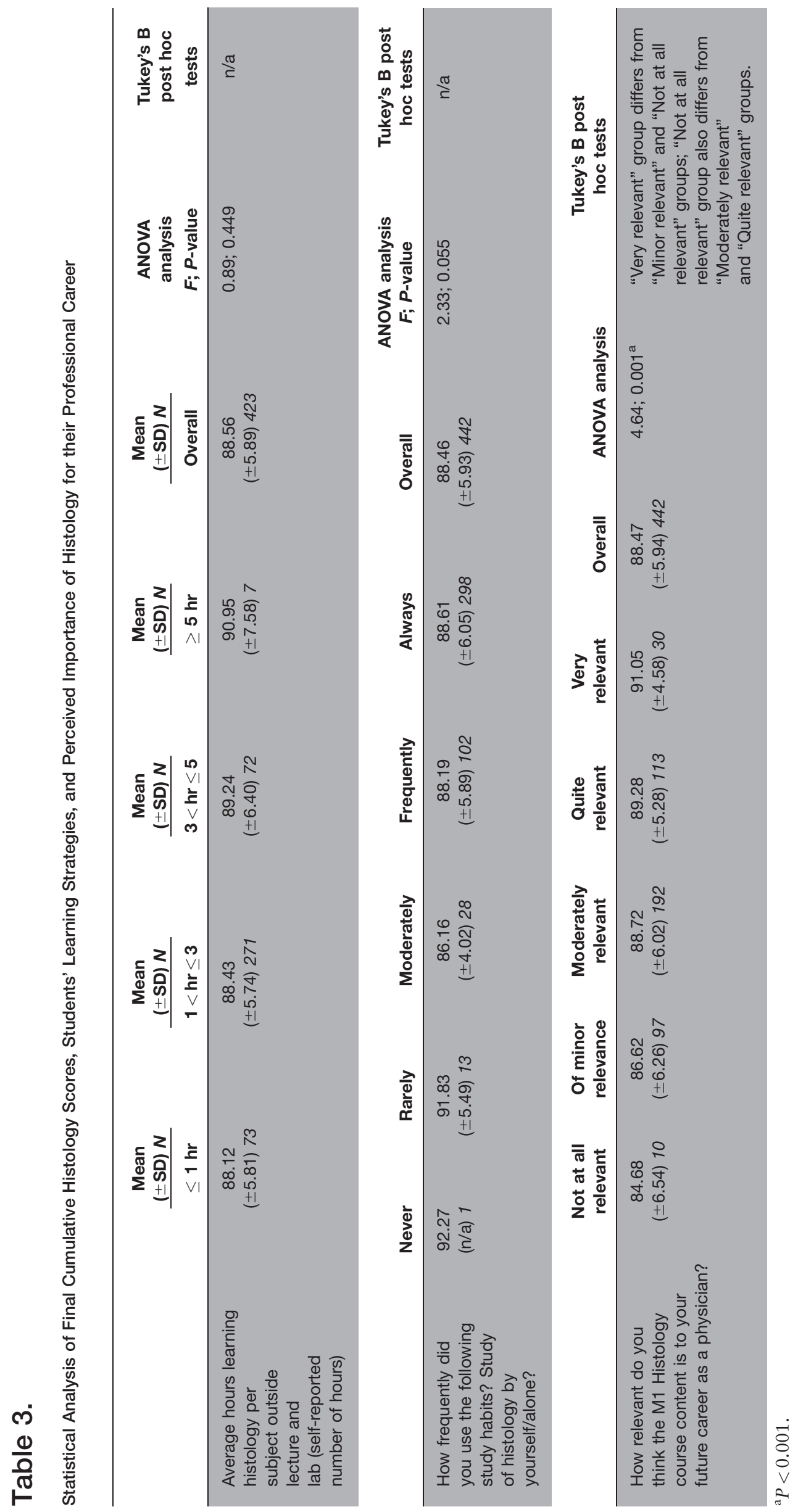




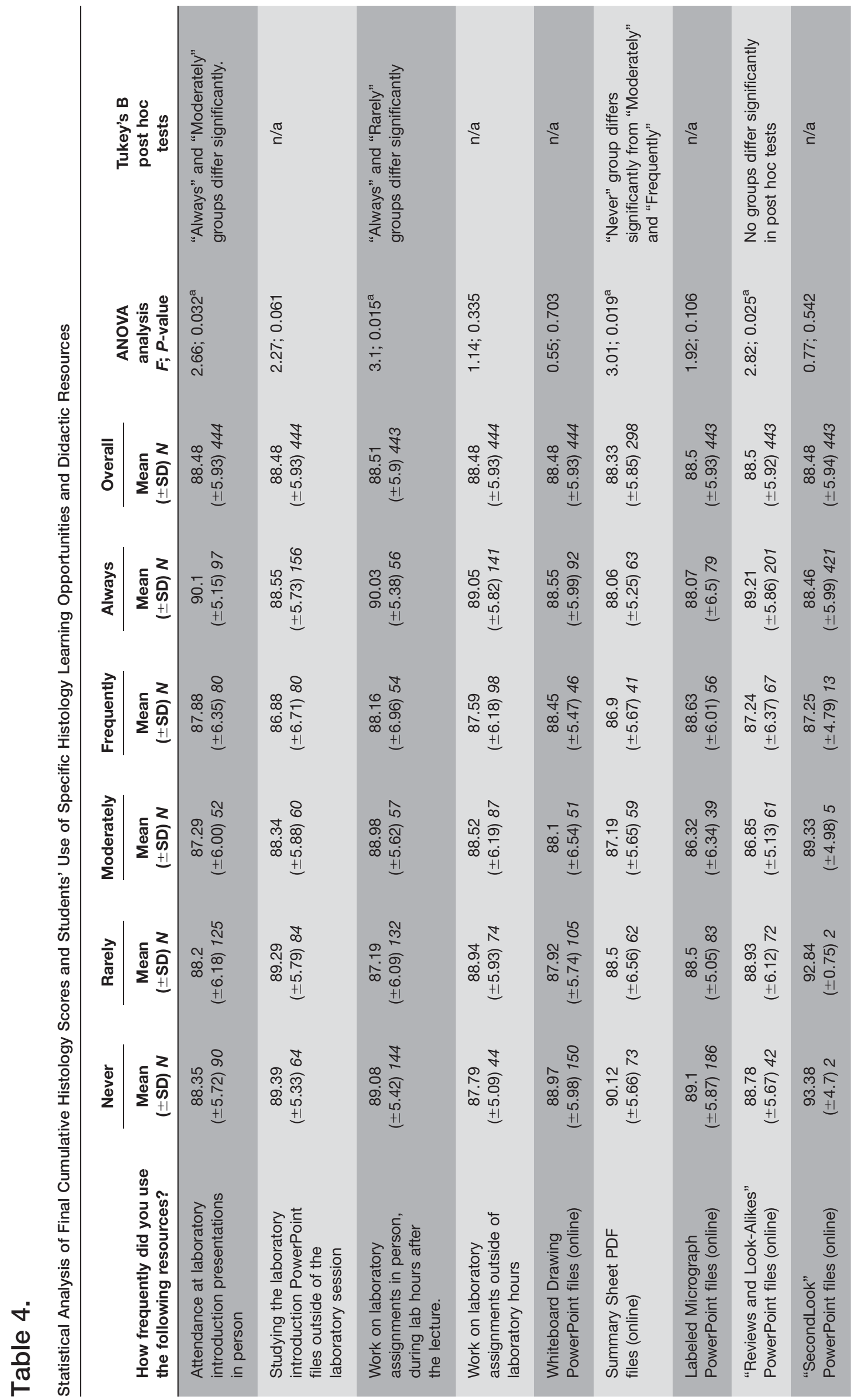




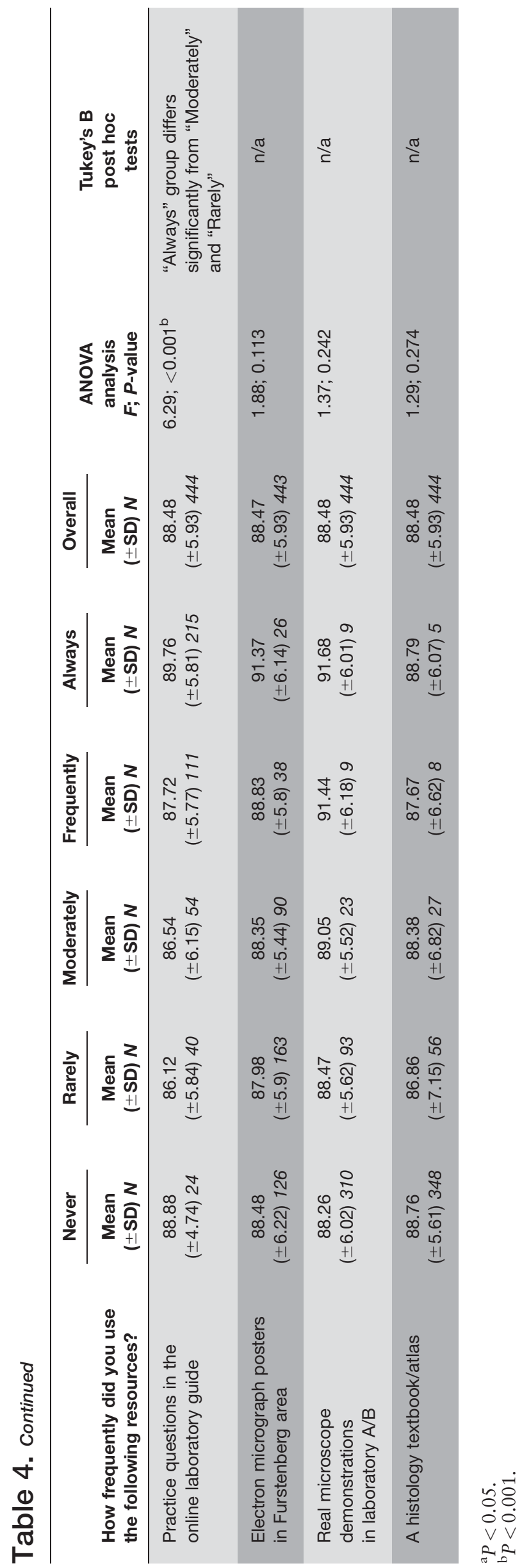

be taken when developing histology teaching resources or formulating histology examination questions to minimize the handicap these students are facing.

\section{Association between Students' Study Attitude/Habits and Final Cumulative Histology Score}

To assess students' motivation to learn histology, students were asked for their view regarding how relevant histology is for their future career as a physician. As one might expect, students who placed a higher relevance on histology as an important component of their medical education had significantly higher final cumulative histology scores than those students who felt histology to be not or only of minor relevance (Table 3). It is well-documented that motivation is an important factor for medical students to develop sophisticated and successful learning strategies (Rhoads et al., 1974; Sobral, 2004; Kusurkar et al., 2011). However, given that this is a retrospective study, it is also possible that students who did well in histology reported they believed it to be relevant to their future career to further reward themselves for their success. One might postulate that motivated students spend more time studying specific subjects, resulting in a better educational outcome. However, no association between self-reported hours of study time for histology and the final cumulative histology score was observed. This result might be due to students who struggle with the material are spending more time studying to compensate and to achieve a passing grade.

Small group learning has been reported to improve academic performance in higher education (Herreid, 1998; Lou et al., 2001). A previous report indicates that University of Michigan first-year medical students overwhelmingly prefer to study histology alone rather than in small groups, a tendency that increases over time (Holaday et al., 2013). Linking the self-reported frequency of studying alone with final cumulative histology examination scores indicates that students, who studied at least occasionally with classmates, score slightly better (Table 3 ). An ANOVA analysis yielded a $P$ value of 0.055 , which approached, but did not breach statistical significance. Again, as the number of students who preferred studying in a group over alone was very small (only 14 students reported to "never" or "rarely" study alone), a larger cohort of surveyed students might shed better light on the effect of small group learning for histology.

\section{Association between Students' Resource Usage and Final Cumulative Histology Score}

As reported previously, first-year medical students generally prefer interactive electronic learning resources for histology over scheduled traditional learning opportunities (Holaday et al., 2013). The use of most of these electronic resources increased as the academic year progressed, whereas traditional didactic resources were used less. Table 4 shows how the reported use of different histology learning resources associates with final cumulative histology scores. As most of the offered supplemental learning resources serve rather specific needs, their use is usually not associated with students' final cumulative histology scores. This is especially true if too few students or almost all students used a specific 


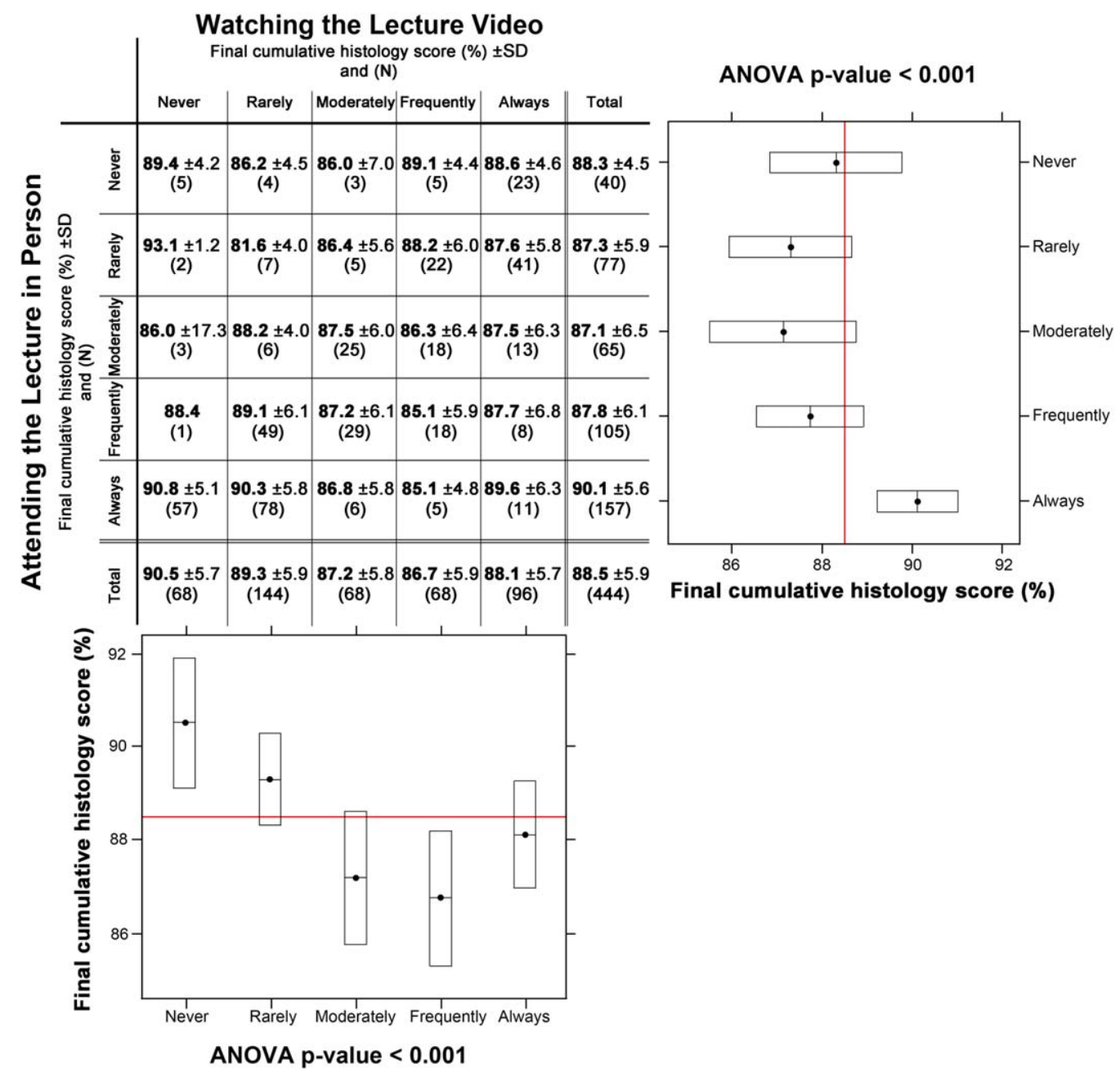

Figure 1.

Final cumulative histology scores of students attending lectures in person and/or using online lecture videos. Numbers in parenthesis indicate the number of students and the bars in the boxes on the right and below represent $95 \%$ confidence intervals. The red lines mark the overall final cumulative histology score average for all survey respondents. ANOVA analyses of students' final cumulative histology scores with reported live lecture attendance and with their use of lecture videos, respectively, both resulted in $P$-values $<0.001$.

resource (e.g., 348 of 444 students reported that they "never" used a histology textbook and the SecondLook resource was "always" used by 421 of 443 students). One notable exception is the use of the sample questions at the end of the histology laboratory webpage, which are highly significantly associated with final cumulative histology scores (Table 4; $P$ value $<0.001)$. As they have a multiple-choice format, they best simulate the actual quiz and examination questions from which the final cumulative histology scores were derived. Attending the laboratory introduction presentation in person and working on the laboratory assignments while faculty members are present to answer questions is significantly associated with a positive learning outcome. This should be a concern as the number of faculty contact hours for teaching histology is decreasing at many North American medical and dental schools (Drake et al., 2009; Burk et al., 2013).

Attending histology lecture presentations in person associates with better final cumulative histology scores at a high level of statistical significance, whereas viewing the lecture video exhibits a highly significant negative association. Video recordings of lectures that can be viewed at any time are very popular with dental and medical students (Nieder and Nagy, 2002; Jham et al., 2008; Holaday et al., 2013). In part, this may be due to students' incorrect assumption that recorded lectures speed up learning (Cardall et al., 2008). However, an earlier report suggests that although lecture video recordings are popular with medical students, they do not improve final grades (Bacro et al., 2010). At many medical schools, including the University of Michigan, the availability of lecture recordings is used as a recruitment tool (Kanter, 2012). The observation that medical students who attend lectures in person achieve significantly better grade point averages and National Board of Medical Examiners (NBME®) Step 1 scores is not new (Sade and Stroud, 1982). However, it should be noted that the study by Sade and Stroud (1982) precedes the availability of lecture video recordings. That makes the result, which associates the use of video recordings with a decrease in histology examination performance, a 
tantalizing observation. Due to a lack of more detailed information, one can only speculate about the reasons for the observed association. It is reasonable to assume that students use lectures and lecture videos in different ways that either foster or discourage learning. As some students use both forms of delivery, and as the availability of lecture videos allows students to view missed lectures and to clarify uncertainties, the results presented here are in agreement with other studies that lecture videos, if used in combination with live lectures, have a useful place in higher learning (Gupta and Saks, 2013). The data depicted in Figure 1 suggest that regardless of their decision whether to attend lectures in person or to view lecture videos, students who "Always" use a chosen learning resource perform better than their peers who do not consistently use a single study method. As reported by Thatcher et al., "Always" attending lectures is the best indicator for academic success in an undergraduate psychology class (Thatcher et al., 2007). A study of Belgian medical students demonstrates that students who score high for conscientiousness in a psychological test perform better in preclinical medical school examinations (Lievens et al., 2002). Therefore, students who are not performing well in a histology course might be well advised to attend lectures and laboratory sessions regularly. These results might even suggest that lecture and laboratory attendance should be compulsory. However, as this might negatively impact students' motivation to learn and to participate, a good case has been made against compulsory class attendance in higher education ( $\mathrm{St}$ Clair, 1999).

\section{Identifying and Advising Histology Learners in Academic Trouble}

The results from this analysis should help in identifying groups of students who might not do well in a histology course. However, it will be up to the course director or the Academic Review Board to single out those individuals, who are performing at or below the required level of expertise and to initiate an effective counseling program that addresses those individuals' needs. At the UMMS, this task falls to the Academic Review Board. Students, who have a cumulative histology quiz and examination score below the required $75 \%$ level, are advised to meet with the histology component director to discuss how they can improve their histology test results. Often these students fall into one or several of the various groups identified as at risk in this study of failing the histology component. Based on the results of this study, we now advise these students to change their study strategy and study habits to emulate those students, who do well in histology. The simple advice to attend lectures and laboratory session in person often results in considerable improvements in the examination scores of individual students and in their motivation to learn histology.

\section{Limitations of the Study}

As this study relies on students' self-reported study habits and use of various histology learning resources, it should be noted that the survey is retrospective in design. Therefore, the numbers should rather be viewed as representative trends rather than exact quantitative measurements of actual students' behavior. However, our own casual observations (lecture and laboratory attendance) and many informal conversations with individual students are in good agreement with the survey answers given by three classes of first-year medical students. Because our report is based on a specific educational environment and curriculum, the range of instructional material and the characteristics of the student population may differ to some extent from other educational institutions. However, a significant number of specific elements are likely to be the same or similar. Therefore, many of the conclusions that can be drawn from the results presented here should equally be applicable to other programs. The conclusions presented here might be helpful in identifying groups of students at other institutions who are at risk of not performing well in a histology course or component. However, as each student has his/her own optimal learning style (Newble and Entwistle, 1986), individualized solutions and learning support will be crucial for effective advising and counseling. Finally, there are many additional nontechnical skills that could influence success in the histology component, for example, communication skills, efficiency, and stress management. However, as these are difficult to measure using a retrospective survey, we were not able to address them directly.

\section{CONCLUSIONS}

This study identifies several factors that are linked to high or low final cumulative histology examination scores of firstyear medical students. A biomedical science college major and previous histology or pathology experiences are positive indicators for learning success in a medical school histology component. The perception that histology is relevant for a successful medical career and the participation in facultyguided learning opportunities are associated with academic success, whereas a view that histology is not relevant to the student's future profession and a reliance on lecture video watching is inversely associated with final cumulative histology scores. These findings should be useful for curriculum development, as well as for identifying students who may require extra resources or support to learn histology.

\section{ACKNOWLEDGMENTS}

The authors report no conflicts of interest and they are alone responsible for the content and writing of the article. The authors would like to acknowledge the contributions made by their colleagues in generating the various learning resources that are available to students at the University of Michigan for learning histology, specifically Drs. Christensen (Whiteboard Drawings), Kim (Reviews and Look-Alikes), Velkey (Labeled Micrographs), and Yamashita (Summary Sheets). The authors are also tremendously grateful to the editors and the reviewers for their detailed and insightful analysis and for their many valuable suggestions how to improve the original manuscript.

\section{NOTES ON CONTRIBUTORS}

DANIEL SELVIG, B.Sc., is a fourth-year medical student in the class of 2014, at the UMMS in Ann Arbor, Michigan. He has an interest in medical education and is looking forward to his residency in Internal Medicine at the University of California, San Francisco.

LOUISA W. HOLADAY, B.G.S., is a third-year medical student in the class of 2015 at the UMMS in Ann Arbor, Michigan. Her research interests are in health disparities, 
increasing diversity in academic medicine, and medical education.

JOEL PURKISS, Ph.D., is the Director of Evaluation and Assessment in the Office of Medical Student Education of the UMMS and a Research Investigator in the Department of Medical Education. His research interests are in medical education curriculum evaluation and improvement, as well as in the prediction of medical education performance outcomes.

MICHAEL HORTSCH, Ph.D., is an associate professor in the Departments of Cell and Developmental Biology and of Medical Education at the UMMS in Ann Arbor, Michigan. Since 1991, he has taught medical and dental histology at the University of Michigan. He is a recipient of the 2012 Kaiser Permanente Award for Excellence in Preclinical Teaching from the UMMS and the 2013 University of Michigan Provost's Teaching Innovation Prize. He is interested in the development of novel electronic teaching tools and how these new resources impact students' learning.

\section{LITERATURE CITED}

Bacro TR, Gebregziabher M, Fitzharris TP. 2010. Evaluation of a lecture recording system in a medical curriculum. Anat Sci Educ 3:300-308.

Bloodgood RA, Ogilvie RW. 2006. Trends in histology laboratory teaching in United States medical schools. Anat Rec 289B:169-175.

Burk DT, Lee LM, Lambert HW. 2013. Embryology and histology education in North American dental schools: The basic science survey series. J Dent Educ 77:744-756.

Canaday SD, Lancaster CJ. 1985. Impact of undergraduate courses on medical student performance in basic sciences. J Med Educ 60:757-763.

Cardall S, Krupat E, Ulrich M. 2008. Live lecture versus video-recorded lecture: Are students voting with their feet? Acad Med 83:1174-1178.

Cleland J, Leggett H, Sandars J, Costa MJ, Patel R, Moffat M. 2013. The remediation challenge: Theoretical and methodological insights from a systematic review. Med Educ 47:242-251.

Dickman RL, Sarnacki RE, Schimpfhauser FT, Katz LA. 1980. Medical students from natural science and nonscience undergraduate backgrounds. Similar academic performance and residency selection. JAMA 243:2506-2509.

Dixon D. 2012. Prediction of osteopathic medical school performance on the basis of MCAT score, GPA, sex, undergraduate major, and undergraduate institution. J Am Osteopath Assoc 112:175-181.

Drake RL, McBride JM, Lachman N, Pawlina W. 2009. Medical education in the anatomical sciences: The winds of change continue to blow. Anat Sci Educ 2:253-259.

Ferguson E, James D, Madeley L. 2002. Factors associated with success in medical school: Systematic review of the literature. BMJ 324:952-957.

Forester JP, McWhorter DL, Cole MS. 2002. The relationship between premedical coursework in gross anatomy and histology and medical school performance in gross anatomy and histology. Clin Anat 15:160-164.

Gupta A, Saks NS. 2013. Exploring medical student decisions regarding attending live lectures and using recorded lectures. Med Teach 35:767-771.

Hamilton PW, van Diest PJ, Williams R, Gallagher AG. 2009. Do we see what we think we see? The complexities of morphological assessment. J Pathol 218: 285-291.

Heidger PM Jr, Dee F, Consoer D, Leaven T, Duncan J, Kreiter C. 2002. Integrated approach to teaching and testing in histology with real and virtual imaging. Anat Rec 269:107-112.

Helle L, Nivala M, Kronqvist P, Ericsson KA, Lehtinen E. 2010. Do prior knowledge, personality and visual perceptual ability predict student performance in microscopic pathology? Med Educ 44:621-629.

Herreid CF. 1998. Why isn't cooperative learning used to teach science? Bioscience 48:553-559.

Holaday L, Selvig D, Purkiss J, Hortsch M. 2013. Preference of interactive electronic versus traditional learning resources by University of Michigan medical students during the first year histology component. Med Sci Educ 23:607619.

Huff KL, Fang D. 1999. When are students most at risk of encountering academic difficulty? A study of the 1992 matriculants to U.S. medical schools. Acad Med 74:454-460.

Husmann PR, O'Loughlin VD, Braun MW. 2009. Quantitative and qualitative changes in teaching histology by means of virtual microscopy in an introductory course in human anatomy. Anat Sci Educ 2:218-226.

Jham BC, Duraes GV, Strassler HE, Sensi LG. 2008. Joining the podcast revolution. J Dent Educ 72:278-281.
Kanter SL. 2012. To be there or not to be there: Is attendance really the question? Acad Med 87:679.

Koenig JA. 1992. Comparison of medical school performances and career plans of students with broad and with science-focused premedical preparation. Acad Med 67:191-196.

Kumar RK, Freeman B, Velan GM, De Permentier PJ. 2006. Integrating histology and histopathology teaching in practical classes using virtual slides. Anat Rec 289B:128-133.

Kusurkar RA, Ten Cate TJ, van Asperen M, Croiset G. 2011. Motivation as an independent and a dependent variable in medical education: A review of the literature. Med Teach 33:e242-e262.

Lei LW, Winn W, Scott C, Farr A. 2005. Evaluation of computer-assisted instruction in histology: Effect of interaction on learning outcome. Anat Rec 284B:28-34.

Lievens F, Coetsier P, De Fruyt F, De Maeseneer J. 2002. Medical students' personality characteristics and academic performance: A five-factor model perspective. Med Educ 36:1050-1056.

Lou YP, Abrami PC, d'Apollonia S. 2001. Small group and individual learning with technology: A meta-analysis. Rev Educ Res 71:449-521.

McLaughlin K, Veale P, McIllwrick J, de Groot J, Wright B. 2013. A practical approach to mentoring students with repeated performance deficiencies. BMC Med Educ 13:56.

Mescher LA. 2013. Junqueira's Basic Histology: Text and Atlas. 13th Ed. New York, NY: McGraw-Hill Companies, Inc. 544 p.

Newble DI, Entwistle NJ. 1986. Learning styles and approaches: Implications for medical education. Med Educ 20:162-175.

Nieder GL, Nagy F. 2002. Analysis of medical students' use of web-based resources for a gross anatomy and embryology course. Clin Anat 15:409-418.

Notzer N, Aronson M. 1979. Differential evaluation of students' performance in histology. All questions are equal but some are more equal than others. Med Educ 13:79-81.

Ogilvie RW, Blue AV, Trusk T. 1999. Computer-administered formative quizzes in a basic science course. Acad Med 74:574-575.

Poole CJ, Hill DJ, Christie JL, Birch J. 1997. Deficient colour vision and interpretation of histopathology slides: Cross sectional study. BMJ 315:1279-1281. Qualtrics. 2014. Qualtrics. Provo, UT. URL: http://www.qualtrics.com/ [accessed 6 March 2014].

Rhoads JM, Gallemore JL Jr, Gianturco DT, Osterhout S. 1974. Motivation, medical school admissions, and student performance. J Med Educ 49:11191127.

Ross MH, Pawlina W. 2011. Histology: A Text and Atlas with Correlated Cell and Molecular Biology. 6th Ed. Baltimore, MD: Lippincott, Williams \& Wilkins. 974 p.

Sade RM, Stroud MR. 1982. Medical student attendance at lectures: Effect on medical school performance. J Med Educ 57:191-192.

Smith SR. 1998. Effect of undergraduate college major on performance in medical school. Acad Med 73:1006-1008.

Sobral DT. 2004. What kind of motivation drives medical students' learning quests? Med Educ 38:950-957.

St Clair KL. 1999. A case against compulsory class attendance policies in higher education. Innov High Educ 23:171-180.

Steele MW, Barnhill BM. 1982. Lack of impact of undergraduate genetic courses on the teaching of medical genetics. Am J Hum Genet 34:501-506.

Stegers-Jager KM, Cohen-Schotanus J, Themmen AP. 2013. The effect of a short integrated study skills programme for first-year medical students at risk of failure: A randomised controlled trial. Med Teach 35:120-126.

Tektas OY, Fiessler C, Mayr A, Neuhuber W, Paulsen F. 2013. Correlation of high school exam grades with study success at a German medical school. J Contemp Med Educ 1:157-162.

Thatcher A, Fridjhon P, Cockcroft K. 2007. The relationship between lecture attendance and academic performance in an undergraduate psychology class. $S$ Afr J Psychol 37:656-660.

Triola MM, Holloway WJ. 2011. Enhanced virtual microscopy for collaborative education. BMC Med Educ 11:4.

UMMS. 2013. University of Michigan medical School. Michigan eHistologyA SecondLook ${ }^{\mathrm{TM}}$ Series. University of Michigan Medical School, Ann Arbor, MI. URL: http://www.med.umich.edu/lrc/secondlook/ [accessed 6 March 2014].

UMMS. 2014. University of Michigan Medical School. Histology and Virtual Microscopy Learning Resources. University of Michigan Medical School, Ann Arbor, MI. URL: http://histology.med.umich.edu/schedule/medical- [accessed 6 March 2014].

Young B, Lowe JS, Stevens A, Heath JW. 2006. Wheater's Functional Histology: A Text and Colour Atlas. 5th Ed. Philadelphia, PA: Churchill Livingstone, Elsevier. 448 p.

Zeleznik C, Hojat M, Veloski J. 1983. Baccalaureate preparation for medical school: Does type of degree make a difference? J Med Educ 58:26-33. 